OPEN ACCESS

Edited by:

Carsten Watzl,

Leibniz Research Centre for Working Environment and Human Factors

(IfADo), Germany

Reviewed by: John Pradeep Veluchamy, VU University Medical Center,

Netherlands

Kerry S. Campbell,

Fox Chase Cancer Center

United States

Christian Kellner,

LMU Munich University Hospital,

Germany

*Correspondence:

Christian Binder

christian.binder@igp.uu.se

Specialty section:

This article was submitted to

NK and Innate Lymphoid

Cell Biology,

a section of the journal

Frontiers in Immunology

Received: 27 August 2020 Accepted: 05 January 2021

Published: 11 February 2021

Citation:

Binder C, Sellberg F, Cvetkovski F, Berg $S$, Berglund $E$ and Berglund $D$ (2021) Siplizumab Induces NK Cell Fratricide Through Antibody-Dependent Cell-Mediated Cytotoxicity.

Front. Immunol. 12:599526. doi: 10.3389/fimmu.2021.599526

\section{Siplizumab Induces NK Cell Fratricide Through Antibody- Dependent Cell-Mediated Cytotoxicity}

\author{
Christian Binder ${ }^{1,2 *}$, Felix Sellberg ${ }^{1,2}$, Filip Cvetkovski ${ }^{2}$, Stefan Berg ${ }^{2}$, Erik Berglund ${ }^{2,3}$ \\ and David Berglund ${ }^{1,2}$ \\ 1 Department of Immunology, Genetics and Pathology, Section of Clinical Immunology, Uppsala University, Uppsala, Sweden, \\ ${ }^{2}$ Research and Development, ITB-Med AB, Stockholm, Sweden, ${ }^{3}$ Division of Transplantation Surgery, Department of Clinical \\ Science, Intervention and Technology (CLINTEC), Karolinska Institute and Karolinska University Hospital, Stockholm, Sweden
}

The glycoprotein CD2 is expressed on T and NK cells and contributes to cell-cell conjugation, agonistic signaling and actin cytoskeleton rearrangement. CD2 has previously been shown to have an important function in natural NK cell cytotoxicity but to be expendable in antibody-mediated cytotoxicity. Siplizumab is a monoclonal anti-CD2 IgG1 antibody that is currently undergoing clinical trials in the field of transplantation. This study investigated the effect of $\mathrm{CD} 2$ binding and $\mathrm{Fc}_{\mathrm{c}} \gamma$ receptor binding by siplizumab (Fcactive) and FC-silent anti-CD2 monoclonal antibodies in allogeneic mixed lymphocyte reaction and autologous lymphocyte culture. Further, induction of NK cell fratricide and inhibition of natural cytotoxicity as well as antibody-dependent cytotoxicity by these agents were assessed. Blockade of CD2 via monoclonal antibodies in the absence of Fc $\gamma$ receptor binding inhibited NK cell activation in allogeneic mixed lymphocyte reaction. In contrast, siplizumab increased NK cell activation in both mixed lymphocyte reaction and autologous lymphocyte culture due to FcyRIIIA binding. However, experiments using purified NK cells did not show an inhibitory effect of CD2 blockade on natural cytotoxicity or antibody-dependent cytotoxicity. Lastly, it was shown that siplizumab induces NK cell fratricide. Concluding, siplizumab is a promising biopharmaceutical drug candidate for depletion of T and NK cells with minimal off-target effects.

Keywords: NK cell, CD2, siplizumab, spontaneous cytotoxicity, antibody-dependent cell-mediated cytotoxicity, NK alloreactivity

\section{INTRODUCTION}

The glycoprotein CD2 (also known as LFA2) is expressed on T and NK cells where it serves as an adhesion and activation receptor (1). In humans, the main binding partner of CD2 is lymphocyte associated antigen 3 (LFA3; also known as CD58) which is broadly expressed, especially on antigenpresenting cells (APCs). CD2-targeting immunotherapy is a promising treatment for organ

\footnotetext{
Abbreviations: ADCC, antibody-dependent cell-mediated cytotoxicity; ANOVA, analysis of variance; APC, antigenpresenting cell; DG, deglycosylated; Fc $\gamma$ R, Fragment crystallizable gamma receptor; FcS, Fc-silent; KIR, killer cell immunoglobulin-like receptor; NKG2D, natural killer group 2D; HLA, human leukocyte antigen; mAb, monoclonal antibody; NK, natural killer; NKIS, NK cell immunological synapse; LFA3, lymphocyte-associated antigen 3; PBMC, peripheral blood mononuclear cells; RA, rheumatoid arthritis; VPD450, violet proliferation dye 450.
} 
transplant recipients and patients suffering from autoimmune diseases [Reviewed in (1)]. Siplizumab is a monoclonal anti-CD2 IgG1 antibody (anti-CD2 IgG1 mAb) that is currently undergoing clinical trials in the field of transplantation (ClinicalTrials.gov Identifier: NCT04311632). While the potent in vitro immune modulatory effects of siplizumab on $\mathrm{T}$ cells have been documented $(2,3)$, no studies published to date address the in vitro effects of siplizumab on NK cells. Previous in vivo evidence showed siplizumab-induced peripheral T and NK cell depletion in primates (4) and human patients (5). Evidence suggests that antibody-dependent cytotoxicity is one depletory mechanism induced by siplizumab; however, the direct effects of siplizumab on NK cells remain incompletely characterized $(3,6)$.

NK cells express activating and inhibitory receptors. The balance of signaling through both sets of receptors is integrated and determines whether mature NK cells remain in a resting state or become activated (7). Thus, NK cell activation can be elicited by a reduction of inhibitory signaling, an increase in activation signaling, or a combination of both.

Among activating NK cell receptors, CD16 is one whose signaling can induce NK cell activation in isolation. Most remaining activating $\mathrm{NK}$ cell receptors require activation in conjunction to elicit NK cell activation. CD16a is a low affinity Fc $\gamma$ receptor $(F c \gamma R)$ and is also known as Fc $\gamma$ RIIIA. NK cell binding to target-bound IgG antibodies via CD16a promotes antibody-dependent cell-mediated cytotoxicity (ADCC). Other activating NK cell receptors include NKG2D, certain killer cell immunoglobulin-like receptors (KIRs) and NKp46 which bind to tumor antigens, foreign HLA and viral proteins, respectively. Most prominent among inhibitory NK cell receptors are KIRs which recognize self-HLA (8). Antibody-independent target cell killing by NK cells is commonly termed natural or spontaneous NK cell cytotoxicity. In addition to Fc $\gamma$ RIIIA, certain NK cell subsets can express two forms of CD32/Fc $\gamma$ RII, Fc $\gamma$ RIIB, and Fc $\gamma$ RIIC (9).

A critical event preceding NK cell cytotoxicity is stable target cell conjugation via cell-cell adhesion molecules (10). Once stable target cell conjugation has occurred and the NK cell immunological synapse (NKIS) has formed, actin cytoskeleton rearrangement proceeds to facilitate transport of lytic vesicles to the NKIS and subsequent release to achieve target cell killing. Examples of adhesion molecules involved in NK-target cell conjugation and NKIS formation are LFA-1 (8) and CD2 (10) binding to ICAM-1 and LFA3 on the target cell, respectively. Even in natural NK cell cytotoxicity CD16 is enriched in the NKIS through interaction with CD2. Abrogation of this interaction between CD2 and CD16 markedly decreases natural NK cell cytotoxicity but does not affect NK-mediated ADCC (11). CD2 has two Ig domains, one membrane distal domain and one membrane proximal domain. The membrane distal domain binds LFA3 but to date the site on CD2 which interacts with CD16 has not been reported. Depending on where CD16 binds to CD2, simultaneous binding of CD2 to both CD16 and LFA3 may be conceivable. The role of CD2 in NK cell biology is incompletely characterized.

Similar to what has been observed during $\mathrm{T}$ cell-antigen presenting cell (APC) conjugation, CD2 accumulates in the immunological synapse that NK cells form upon target cell conjugation. While the CD2-CD58 interaction has traditionally been known for its role in cellular adhesion, recent evidence has demonstrated that it also plays an important role in recruiting and organizing activating receptors to the immunological synapse $(11,12)$.

This study aimed to characterize the effects of siplizumab on NK cell activation in mixed lymphocyte reaction (MLR) and in pure NK cell culture. Further, potential effects of CD2 blockade on natural cytotoxicity and ADCC were investigated.

\section{MATERIALS AND METHODS}

\section{Generation of Fc-Silent Anti-CD2 Antibodies}

Siplizumab (humanized anti-CD2 IgG1 $)$ is an investigational drug and was provided by the manufacturer (ITB-Med, Stockholm, Sweden).

Deglycosylated (DG) siplizumab was produced using GlycINATOR $^{\circledR}$ (EndoS2; Genovis \#A0-GL1-020) according to the manufacturer's instructions (Genovis AB, Lund, Sweden).

Fc-silent (FcS) anti-CD2 mAbs were generated via introduction of amino acid substitutions into the sequence of siplizumab or standard IgG2/IgG4 frameworks. All Fc-silent antibodies had identical light chains and complementaritydetermining regions and were produced by Wuxi Biologics Limited (Wuxi, China). Genetic sequences for each antibody were cloned into plasmids followed by transient transfection and production in Chinese hamster ovary ( $\mathrm{CHO}-\mathrm{K} 1)$ cells. Anti-CD2 mAbs were purified using protein A and IEX/SEC columns to at least $95 \%$ purity and endotoxin levels below 1 $\mathrm{EU} / \mathrm{mg}$. Fc-silent siplizumab (FcS anti-CD2 IgG1) was generated by introducing the commonly known LALA-PG mutations to equivalent sites in siplizumab $(13,14)$. FcS antiCD2 IgG2 was generated by introducing the following mutations at equivalent sites in a standard IgG2 framework: V234A, G237A P238S, H268A, V309L, A330S, P331S (15). FcS anti-CD2 IgG4 was generated by introducing the following mutations at equivalent sites in a standard IgG4 framework: S228P, L235E, P329G $(16,17)$.

\section{Surface Plasmon Resonance CD2 Binding}

Interaction experiments were performed using a Biacore T200 instrument (Cytiva Life Sciences/Biacore, Uppsala, Sweden). IgG was immobilized to a surface density of 200-1300 RU using standard amine coupling and CM5 biosensor chips (Cytiva Life Sciences/Biacore, Uppsala, Sweden) with a $10 \mathrm{mM}$ HEPES buffer at $\mathrm{pH} 7.4$, with $150 \mathrm{mM} \mathrm{NaCl}, 0.5 \mathrm{mM}$ EDTA, $0.05 \%$ Tween 20 running buffer. Each antibody was immobilized at least twice.

All interaction experiments were performed at $25^{\circ} \mathrm{C}$. Recombinant truncated human CD2 (Sino Biological, Beijing, China) was diluted in two-fold dilution series with the highest concentration being $5 \mathrm{nM}$ and injected for $180 \mathrm{~s}$ over immobilized IgG. After 15 min of dissociation, the sensor chip was regenerated by $30 \mathrm{~s}$ injection of $10 \mathrm{mM}$ glycine $\mathrm{pH}$ 1.7. 
Sensorgrams from reference surfaces and blank injections were subtracted from the raw data prior to data analysis. A two-state (induced fit) interaction model was fitted to the data using T200 evaluation software v3.0 (Cytiva Life Sciences/Biacore, Uppsala, Sweden) to determine kinetic rate constants and affinities.

\section{SPR Fc $\gamma R$ Binding}

Recombinant truncated human CD2 (Sino Biological, Beijing, China) was covalently immobilized by amine coupling to CM5 biosensor chips (Cytiva Life Sciences/Biacore, Uppsala, Sweden). IgG was captured to amine coupled CD2. All experiments were performed using a Biacore $\mathrm{T} 200^{\mathrm{TM}}$ instrument (Cytiva Life Sciences/Biacore, Uppsala, Sweden) at $25^{\circ} \mathrm{C}$. The characterization of compound interactions were conducted in a 10 mM HEPES

buffer at $\mathrm{pH}$ 7.4, with $150 \mathrm{mM} \mathrm{NaCl}, 0.5 \mathrm{mM}$ EDTA, $0.05 \%$ Tween20. Fc $\gamma$ receptors (R\&D systems, Minneapolis USA) were injected for $120 \mathrm{~s}$ in multi-cycle or single-cycle experiments in concentration series up to $0.5 \mu \mathrm{M}$ over CD2-captured IgGs. The R131 isoform of FcyRIIA and V176 isoform of FcyRIIIA were used for all experiments. CD2 surfaces were regenerated by a $120 \mathrm{~s}$ injection of $50 \mathrm{mM} \mathrm{NaOH}$. Sensorgrams were doublereferenced (reference surface, blanks) prior to global analysis using a 1:1 interaction model or a heterogeneous binding model. For weaker interactions with fast dissociation the affinity was determined by steady state analysis using a sum of a Langmuir isotherm and a linear term (compensating for non-specific interaction). Kinetic parameters were determined as average values based on 2-3 replicate experimental series.

\section{Cell-Based FcyR Signaling Assay}

Jurkat reporter cell lines (Promega Corp., Madison, Wisconsin USA) transfected with Fc $\gamma$ RI, Fc $\gamma$ RIIA or Fc $\gamma$ RIIIA, respectively, were incubated with serial dilutions of each antibody agent for $23 \mathrm{~h}$. Binding of a target-bound antibody through the respective $\mathrm{Fc} \gamma \mathrm{R}$ induced expression of luciferase in reporter cells. Luciferase expression was detected after $23 \mathrm{~h}$ of incubation at $37^{\circ} \mathrm{C} 5 \% \mathrm{CO}_{2}$ via addition of luciferase assay substrate (Promega Corp., Madison, Wisconsin USA) and luminescence measurement using a Synergy HTX multiplate reader (BioTek, Winooski, Vermont USA).

\section{Isolation of Peripheral Blood Mononuclear Cells}

Peripheral blood mononuclear cells (PBMC) were isolated via Ficoll $^{\circledR}$ Paque Plus (Cytiva Life Sciences, Uppsala, Sweden) density gradient centrifugation from buffy coats. Buffy coats were obtained from healthy donors via Uppsala University Hospital blood bank (Uppsala, Sweden) as well as Karolinska University Hospital blood bank (Stockholm, Sweden) and PBMC isolation was carried out within $24 \mathrm{~h}$ of blood collection.

\section{CD2 Expression Analysis}

Resting PBMC were stained and analyzed for target antigen expression. Subsequently, PBMC in autologous culture were activated via CD28/CD3 beads (Miltenyi, Bergisch Gladbach, Germany; bead to cell ratio 5:1) for $48 \mathrm{~h}$ and cultured in $10 \%$ heat-inactivated fetal bovine serum (FBS; Gibco, Thermo Fisher Scientific Inc., Waltham, USA) in RPMI-1640 ATCC Mod. supplemented with $50 \mathrm{U} / \mathrm{ml}$ Streptomycin and Penicillin (Gibco, Thermo Fisher Scientific Inc., Waltham, USA) and target antigen expression was investigated.

PBMC were washed twice in saline solution. Samples were incubated with Fc-receptor binding inhibitor (Invitrogen; Thermo Fisher Scientific Inc., Waltham, USA) and then washed twice in FBS stain buffer (BD BioSciences, San Diego, USA) followed by incubation with $10 \mu \mathrm{g} / \mathrm{ml}$ siplizumab for $20 \mathrm{~min}$. Unbound antibody was removed before staining with secondary anti-human IgG Fc BV421 (BioLegend, San Diego, USA; Clone HP6017). Unbound secondary antibody was removed before surface staining for $\mathrm{T}$ cell subpopulations, regulatory $\mathrm{T}$ cells or $\mathrm{B}$ and $\mathrm{NK}$ cells. All antibodies listed below were purchased from BD Biosciences (San Diego, USA) if not indicated otherwise.

Samples to be used for analysis of $\mathrm{T}$ cell subpopulation distribution were stained with anti-CD3 PerCP (Clone SK7), anti-CD4 FITC (Clone SK3) and anti-CD8 PE (Clone SK1), with anti-CCR7 Alexa647 (Clone 3D12) and anti-CD45RA APC-H7 (Clone HI100) (Naïve T cells: $\mathrm{CCR}^{+} \mathrm{CD}^{2} \mathrm{RA}^{+}$; Central memory $\mathrm{T}$ cells: $\mathrm{CCR}^{+} \mathrm{CD}^{+} 5 \mathrm{RA}^{-}$; Effector memory $\mathrm{T}$ cells: CCR7- CD45RA'; Terminally-differentiated effector memory $\mathrm{T}$ cells (Temra): CCR7- CD45RA ${ }^{+}$).

Samples that analyzed Tregs were stained anti-CD4 FITC (Clone RPA-T4), anti-CD25 PE (Clone M-A251), anti-CD45RA APC-H7 (Clone HI100), anti-CD127 PerCP-Cy5.5 (Clone HIL7R-M21) and anti-FoxP3 Alexa647 (Clone 259D/C7). They were permeabilized using BD Human FoxP3 Buffer Set (BD BioSciences, San Diego, USA) according to the vendor's protocol. Tregs were identified as $\mathrm{CD}^{+} \mathrm{CD} 127^{-} \mathrm{CD}^{+} 5^{+} \mathrm{FoxP}^{+}$.

NK/B cell panel consisted of anti-CD16 FITC (Clone 3G8), anti-CD56 PE (Miltenyi, Bergisch Gladbach, Germany; Clone REA196), anti-CD3 APC (Clone SK7) anti-CD14 APC-H7 (Clone M5E2), and anti-CD20 PerCP (Clone SJ25C1).

Samples were stained in the dark at $4^{\circ} \mathrm{C}$ and were acquired using a FACSVerse flow cytometer (BD Biosciences, San Diego, USA). Post-acquisition editing and data analysis was conducted using FlowJo ${ }^{\circledR} 10.5 .3$ software (FlowJo LLC, Ashland, USA).

\section{FcyR Expression Analysis}

NK cells were isolated via negative magnetic bead selection using NK cell isolation kit (Miltenyi, Bergisch Gladbach, Germany) according to the manufacturer's instructions. A fraction of NK cells were washed twice in saline solution and stained with antiCD56 BV421 (Clone NACM16.2), anti-CD3 VioGreen (Miltenyi, Bergisch Gladbach, Germany; Clone REA613), anti-CD16 FITC (Miltenyi, Bergisch Gladbach, Germany; Clone REA423), antiCD32 PE (Miltenyi, Bergisch Gladbach, Germany; Clone REA997), and anti-CD64 APC (Miltenyi, Bergisch Gladbach, Germany; Clone REA978). Samples were stained in the dark at $4^{\circ} \mathrm{C}$ and were acquired using a FACSCelesta flow cytometer (BD Biosciences, San Diego, USA). Post-acquisition editing and data analysis was conducted using FlowJo ${ }^{\circledR}$ 10.6.2 software (FlowJo LLC, Ashland, USA). NK cells were defined as $\mathrm{CD}^{-} \mathrm{CD}^{-} 6^{+}$and/ or $\mathrm{CD}_{16}{ }^{+}$lymphocytes. 


\section{Autologous Lymphocyte Culture and Mixed Lymphocyte Reaction}

For analysis of NK cell activation over time in the presence of siplizumab and DG siplizumab, equal amounts of PBMC from each donor were stained with violet proliferation dye 450 (BD Biosciences, San Diego, USA; VPD450) for another experiment. Cells were resuspended in 10\% heat-inactivated FBS (Gibco, Thermo Fisher Scientific Inc., Waltham, USA) in RPMI-1640 ATCC Mod. supplemented with $50 \mathrm{U} / \mathrm{ml}$ Streptomycin and Penicillin (Gibco, Thermo Fisher Scientific Inc., Waltham, USA), respectively. Resuspended PBMC were dispensed into round-bottom 96-well cell culture plates and pure medium (no antibody controls) or one of the respective antibody agents diluted in cell culture medium $(10 \mu \mathrm{g} / \mathrm{ml})$ was added to a final concentration of $2 \times 10^{6}$ cells per ml (final volume $200 \mu \mathrm{l}$ ). ALCs and MLRs were then incubated at $37^{\circ} \mathrm{C} 5 \% \mathrm{CO}_{2}$ for 1,2 , 4, and 7 days, respectively. On each day, cells were washed twice in saline solution and incubated with Fc-receptor binding inhibitor (Invitrogen; Thermo Fisher Scientific Inc., Waltham, USA) followed by staining with anti-CD16 FITC (Clone 3G8), antiCD56 PE (Miltenyi, Bergisch Gladbach, Germany; Clone REA196), anti-CD3 PerCP-Cy5.5 (Clone SP34-2), anti-CD69 APC (Clone FN50) and anti-CD14 APC-H7 (Clone M $\varphi$ P-9). NK cells were identified as $\mathrm{CD}^{-} \mathrm{CD}^{-} 4^{-} \mathrm{CD}^{+} 6^{+}$and/or $\mathrm{CD} 16^{+}$ lymphocytes. All flow cytometry antibodies were purchased from BD Biosciences (San Diego, USA) if not indicated otherwise. Samples were stained in the dark at $4^{\circ} \mathrm{C}$ and were acquired using a FACSVerse flow cytometer (BD Biosciences, San Diego, USA). Post-acquisition editing and data analysis was conducted using FlowJo ${ }^{\circledR}$ 10.5.3 software (FlowJo LLC, Ashland, USA).

For analysis of NK cell activation after 7 days in the presence of different anti-CD2 variants, equal amounts of PBMC from each donor were stained with VPD450 for another experiment. Cells were resuspended in 10\% heat-inactivated FBS (Gibco, Thermo Fisher Scientific Inc., Waltham, USA) in AIM-V medium supplemented with $50 \mu \mathrm{g} / \mathrm{ml}$ streptomycin sulfate and $10 \mu \mathrm{g} / \mathrm{ml}$ gentamicin sulfate (Gibco, Thermo Fisher Scientific Inc., Waltham), respectively. Resuspended PBMC were dispensed into round-bottom 96-well cell culture plates and pure medium (No antibody controls) or one of the respective antibody agents diluted in cell culture medium $(10-0.0001 \mu \mathrm{g} / \mathrm{ml})$ was added to a final concentration of $2 \times 10^{6}$ cells per $\mathrm{ml}$ (final volume $200 \mu \mathrm{l}$ ). MLRs were then incubated at $37^{\circ} \mathrm{C} 5 \% \mathrm{CO}_{2}$ for 7 days, respectively. Fresh culture medium $(100 \mu \mathrm{l})$ was added to each well on day 5 . On day 7 , cells were washed twice in saline solution and incubated with Fc-receptor binding inhibitor (Invitrogen; Thermo Fisher Scientific Inc., Waltham, USA) followed by staining with anti-CD3 VioGreen (Miltenyi, Bergisch Gladbach, Germany; Clone REA613), anti-CD45RA BV650 (Clone HI100), anti-CD69 BV786 (Clone FN50), antiCD8 BB550 (Clone RPA-T8), anti-CD56 PE (Miltenyi, Bergisch Gladbach, Germany; Clone REA196), anti-CD2 PE-CF594 (Clone RPA-2.10; Note: This clone binds a different CD2 epitope than siplizumab), anti-CCR7 APC (BioLegend, San Diego, USA; Clone G043H7), and anti-CD4 APC-Vio770
(Miltenyi, Bergisch Gladbach, Germany; Clone REA623). NK cells were identified as $\mathrm{CD}^{-} \mathrm{CD}^{-} 6^{+}$lymphocytes. Remaining colors were used for another experiment. All flow cytometry antibodies were purchased from BD Biosciences (San Diego, USA) if not indicated otherwise. Samples were stained in the dark at $4^{\circ} \mathrm{C}$ and were acquired using a FACSCelesta flow cytometer (BD Biosciences, San Diego, USA). Post-acquisition editing and data analysis was conducted using FlowJo ${ }^{\circledR}$ 10.6.2 software (FlowJo LLC, Ashland, USA).

\section{NK Fratricide}

NK cells were isolated from PBMC via negative MACS selection using NK cell isolation kit (Miltenyi, Bergisch Gladbach, Germany). NK cells were resuspended in $10 \%$ heat-inactivated FBS (Gibco, Thermo Fisher Scientific Inc., Waltham, USA) in AIM-V medium supplemented with $50 \mu \mathrm{g} / \mathrm{ml}$ streptomycin sulfate and $10 \mu \mathrm{g} / \mathrm{ml}$ gentamicin sulfate (Gibco, Thermo Fisher Scientific Inc., Waltham) as well as $500 \mathrm{IU} / \mathrm{ml}$ human IL-2 (Miltenyi, Bergisch Gladbach, Germany) and, depending on yield, dispensed into round-bottom 96 -well cell culture plates at a final density between $1.25 \times 10^{6}$ and $2.0 \times 10^{6} \mathrm{NK}$ cells per $\mathrm{ml}$. Further, pure medium (No antibody controls) or one of the respective antibody agents diluted in cell culture medium (final concentration $10-0.001 \mu \mathrm{g} / \mathrm{ml}$ ) was added followed by overnight incubation at $37^{\circ} \mathrm{C} 5 \% \mathrm{CO}_{2}$. Subsequently, NK cells were washed in saline solution followed by incubation with Fc-receptor binding inhibitor (Invitrogen; Thermo Fisher Scientific Inc., Waltham, USA) and staining with anti-CD3 VioGreen (Miltenyi, Bergisch Gladbach, Germany; Clone REA613), antiCD107a BV786 (BioLegend, San Diego, USA; Clone H4A3), anti-CD16 FITC (Miltenyi, Bergisch Gladbach, Germany; Clone REA423), anti-CD56 PE (Miltenyi, Bergisch Gladbach, Germany; Clone REA196), 7-AAD (Invitrogen; Thermo Fisher Scientific Inc., Waltham, USA) and anti-CD69 APC (Miltenyi, Bergisch Gladbach, Germany; Clone REA824). NK cells were identified as $\mathrm{CD}^{-} \mathrm{CD}^{-} 6^{+}$and/or CD16 $6^{+}$lymphocytes. Samples were stained in the dark at $4^{\circ} \mathrm{C}$ and were acquired using a FACSCelesta flow cytometer (BD Biosciences, San Diego, USA). Post-acquisition editing and data analysis was conducted using FlowJo ${ }^{\circledR}$ 10.6.2 software (FlowJo LLC, Ashland, USA).

\section{Natural Cytotoxicity Assay}

NK cells were isolated from PBMC via negative MACS selection using NK cell isolation kit (Miltenyi, Bergisch Gladbach, Germany).

For runs with short pre-incubation, NK cells were resuspended in 10\% heat-inactivated FBS (Gibco, Thermo Fisher Scientific Inc., Waltham, USA) in AIM-V medium supplemented with $50 \mu \mathrm{g} / \mathrm{ml}$ streptomycin sulfate and $10 \mu \mathrm{g} /$ ml gentamicin sulfate (Gibco, Thermo Fisher Scientific Inc., Waltham) and dispensed into round-bottom 96-well cell culture plates followed by resting at $37^{\circ} \mathrm{C} 5 \% \mathrm{CO}_{2}$ overnight. Following, pure medium (no antibody controls) or one of the respective antibody agents diluted in cell culture medium (final concentration $10-0.001 \mu \mathrm{g} / \mathrm{ml}$ ) were added followed by $30 \mathrm{~min}$ incubation at $37^{\circ} \mathrm{C} 5 \% \mathrm{CO}_{2}$ before addition of HLA class Inegative target cells (SPI-801, DSMZ Cat. ACC 86; NK cell to 
target cell ratio between 1:1 and 1:2 depending on yield of MACS isolation). Addition of target cells was followed by incubation at $37^{\circ} \mathrm{C} 5 \% \mathrm{CO}_{2}$ for $2 \mathrm{~h}$ and subsequent flow cytometry staining as described in NK Fratricide section.

For runs with pre-incubation of NK cells with antibody, NK cells were resuspended in in 10\% heat-inactivated FBS (Gibco, Thermo Fisher Scientific Inc., Waltham, USA) in AIM-V medium supplemented with $50 \mu \mathrm{g} / \mathrm{ml}$ streptomycin sulfate and $10 \mu \mathrm{g} / \mathrm{ml}$ gentamicin sulfate (Gibco, Thermo Fisher Scientific Inc., Waltham) as well as $500 \mathrm{IU} / \mathrm{ml}$ human IL-2 (Miltenyi, Bergisch Gladbach, Germany). Further, pure medium (No antibody controls) or one of the respective antibody agents diluted in cell culture medium (final concentration 10-0.001 $\mu \mathrm{g} / \mathrm{ml}$ ) were added followed by incubation at $37^{\circ} \mathrm{C} 5 \% \mathrm{CO}_{2}$ for 2 days. On day 2, HLA class I-negative target cells were added (SPI-801; NK cell to target cell ratio between 1:1 and 1:2 depending on yield of MACS isolation) followed by incubation at $37^{\circ} \mathrm{C} 5 \% \mathrm{CO}_{2}$ for $2 \mathrm{~h}$ and subsequent flow cytometry staining as described in NK Fratricide section.

\section{Rituximab-Induced ADCC Assay}

NK cells were isolated from PBMC via negative MACS selection using NK cell isolation kit (Miltenyi, Bergisch Gladbach, Germany). resuspended in 10\% heat-inactivated FBS (Gibco, Thermo Fisher Scientific Inc., Waltham, USA) in AIM-V medium supplemented with $50 \mu \mathrm{g} / \mathrm{ml}$ streptomycin sulfate and $10 \mu \mathrm{g} / \mathrm{ml}$ gentamicin sulfate (Gibco, Thermo Fisher Scientific Inc., Waltham) and dispensed into roundbottom 96-well cell culture plates. Further, pure medium (No antibody controls) or one of the respective anti-CD2 antibody agents diluted in cell culture medium (final concentration $10 \mu \mathrm{g} / \mathrm{ml}$ ) were added followed by overnight incubation at $37^{\circ} \mathrm{C} 5 \% \mathrm{CO}_{2}$. The next day Daudi target cells (DSMZ Cat. ACC 78; CD20 ${ }^{+}$; NK to Daudi ratio 4:1) and Rituximab (final concentration $0.0001-1 \mu \mathrm{g} / \mathrm{ml}$ ) were added followed by $2 \mathrm{~h}$ of incubation at $37^{\circ} \mathrm{C} 5 \% \mathrm{CO}_{2}$. Subsequently, cells were washed in saline solution and incubated with Fc-receptor binding inhibitor (Invitrogen; Thermo Fisher Scientific Inc., Waltham, USA) followed by staining with anti-CD56 BV421 (BD Biosciences, San Diego, USA; Clone NCAM16.2), anti-CD3 VioGreen (Miltenyi, Bergisch Gladbach, Germany; Clone REA613), anti-CD107a BV786 (BioLegend, San Diego, USA; Clone H4A3), anti-CD16 FITC (Miltenyi, Bergisch Gladbach, Germany; Clone REA423), anti-CD2 PE-CF594 (BD Biosciences, San Diego, USA; Clone RPA-2.10), anti-CD69 APC (Miltenyi, Bergisch Gladbach, Germany; Clone REA824), and
anti-CD19 APC-H7 (BD Biosciences, San Diego, USA; Clone SJ25C1). NK cells were identified as $\mathrm{CD}^{-} \mathrm{CD}^{-} 6^{+}$and/or $\mathrm{CD} 16^{+}$ lymphocytes. Samples were stained in the dark at $4^{\circ} \mathrm{C}$ and were acquired using a FACSCelesta flow cytometer (BD Biosciences, San Diego, USA). Post-acquisition editing and data analysis was conducted using FlowJo ${ }^{\circledR}$ 10.6.2 software (FlowJo LLC, Ashland, USA).

\section{Graphs and Statistical Analysis}

Visualization of results and statistical analysis of underlying data were carried out using GraphPad Prism 8 software (GraphPad Software, San Diego). Data were analyzed using repeatedmeasure one-way ANOVA followed by Dunnett's multiple comparison test or two-way ANOVA followed by Dunnett's multiple comparison test unless specified otherwise. Untreated controls served as the comparator if not specified otherwise.

\section{RESULTS}

\section{CD2 and Fc Gamma Receptor Binding}

Anti-CD2 antibody binding to CD2 and Fc $\gamma \mathrm{R}$ binding was characterized via surface plasmon resonance (SPR). As shown in Table 1, all tested antibodies displayed a similar CD2 binding affinity with an affinity constant $\left(\mathrm{K}_{\mathrm{D}}\right)$ of circa $0.9-1.5 \mathrm{nM}$.

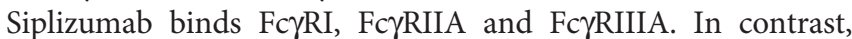
deglycosylated (DG) siplizumab binds Fc $\gamma$ RI but not Fc $\gamma$ RIIA and FcyRIIIA. All three Fc-silent anti-CD2 antibodies did not display detectable Fc $\gamma$ R affinity.

To confirm that Fc $\gamma \mathrm{R}$-binding results in Fc $\gamma \mathrm{R}$-induced signaling, each antibody was tested in a cell-based Fc $\gamma \mathrm{R}$ signaling assay (Supplementary Tables S1-S3). As shown in Figure 1, consistent with SPR results siplizumab induced signaling through Fc $\gamma R$ I, Fc $\gamma$ RIIA and Fc $\gamma$ RIIIA. In contrast, DG siplizumab only induced signaling through Fc $\gamma$ RI. None of the Fc-silenced anti-CD2 variants induced Fc $\gamma \mathrm{R}$ mediated signaling.

\section{CD2 and FcyR Expression on NK Cells}

CD2 expression on NK cells was measured via flow cytometry. As shown in Figure 2A, NK cells tend to have a lower CD2 expression than T cells. While CD56 $6^{\text {bright }}$ NK cells express CD2 at comparable levels as the average $\mathrm{T}$ cell, CD56 ${ }^{\mathrm{dim}}$ and $\mathrm{CD} 6^{\text {neg }} \mathrm{CD}^{+} 6^{+} \mathrm{NK}$ cells express CD2 at significantly lower levels ( $\mathrm{p}=0.0074$ and $\mathrm{p}=0.0111$, respectively; Repeated-measure

TABLE 1 | Affinity of different anti-CD2 antibodies for CD2 and Fc gamma receptor (FcyR) I, IIA and IIIA.

\begin{tabular}{lcccc}
\hline $\boldsymbol{K}_{\boldsymbol{D}}{ }^{(\mathbf{a})}$ & Siplizumab & $\mathbf{D G}^{(\mathbf{b})}$ siplizumab & FcS $^{(\mathbf{c})} \mathbf{I g G} \mathbf{1}$ & FcS IgG2 \\
\hline CD2 & 1.2 & 1.2 & 1.5 & FcS IgG4 \\
Fc gamma RI & 0.2 & 1.13 & $>2000$ & 0.9 \\
Fc gamma RIIA & 579 & $>5000$ & $>5000$ & $>2000$ \\
Fc gamma RIIIA & 131 & $>2000$ & $>5000$ & $>5000$ \\
\hline
\end{tabular}

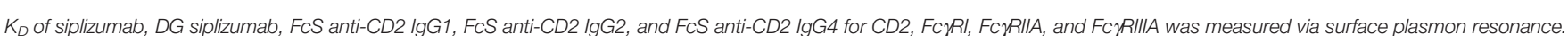

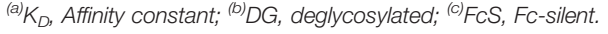


A

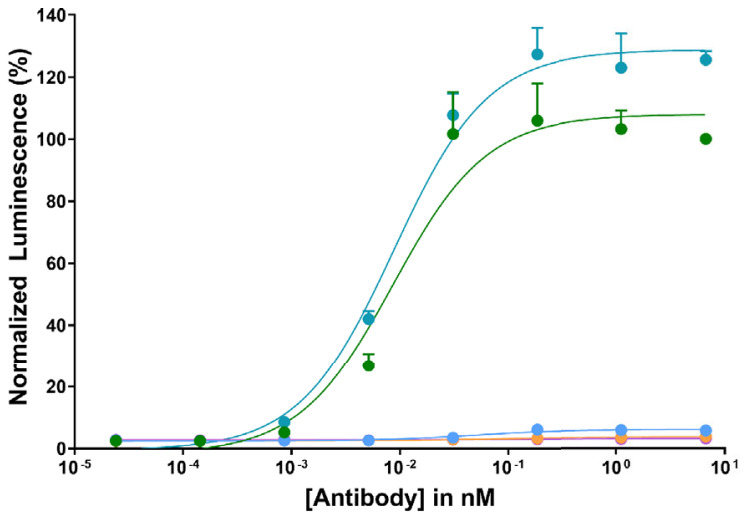

B

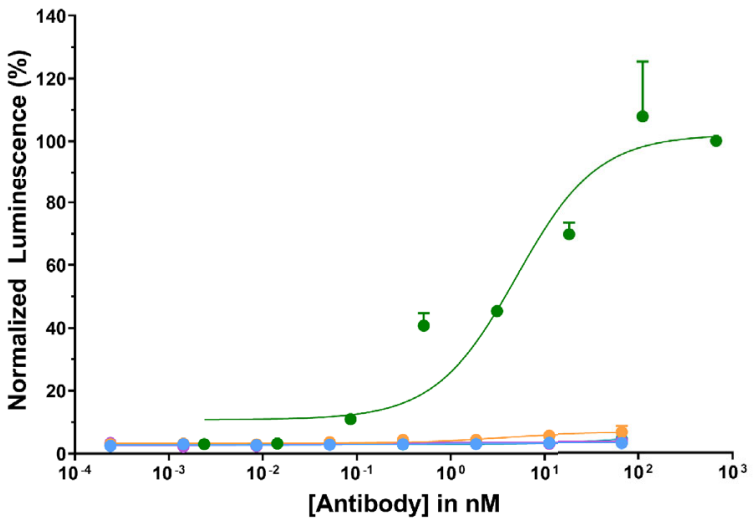

C

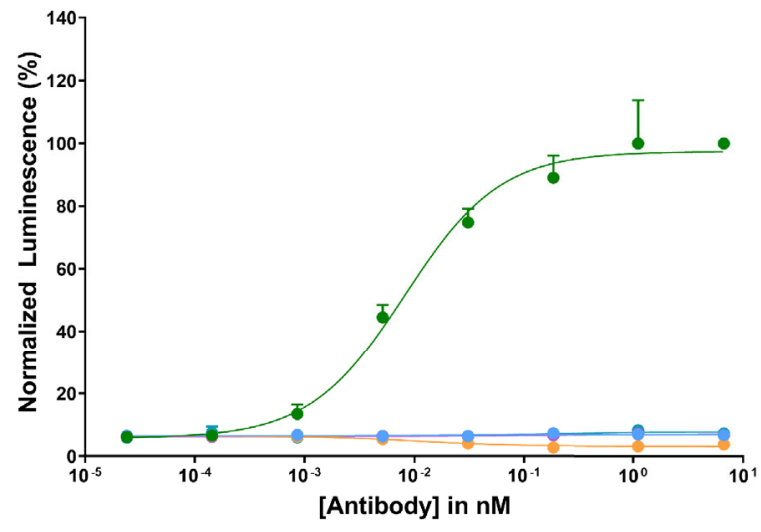

Siplizumab DG Siplizumab

\section{FcS anti-CD2 IgG1 FcS anti-CD2 IgG2}

FcS anti-CD2 IgG4

FIGURE 1 | Jurkat reporter cells (Promega) stably expressing Fc $\gamma$ receptor (FcyR) I, FcyRIIA or FcyRIIIA, respectively, were incubated with increasing concentrations of anti-CD2 antibody. Data normalized to luminescence induced by the highest concentration of siplizumab (mean \pm SD; $n=3$ ). Reporter cells bind the Fc-fragment of a target-bound lgG antibody with their FcyR which induces expression of a luciferase reporter gene resulting in a luminescence signal upon addition of assay substrate (Promega). Cells were incubated with increasing doses of siplizumab, deglycosylated (DG) siplizumab, Fc-silent (FcS) anti-CD2 lgG1, FcS anti-CD2 IgG2 and FCS anti-CD2 lgG4, respectively. (A) Cell-based FcyRl signaling assay. (B) Cell-based FcyRllA signaling assay. (C) Cell-based FcyRIIIA signaling assay.

one-way ANOVA followed by Dunnett's multiple comparison test; Supplementary Table S4). Nevertheless, NK cells show notable CD2 expression when compared to $\mathrm{CD} 2^{-}$cell types, e.g. B cells.
Additionally, CD2 expression on $\mathrm{T}$ and $\mathrm{NK}$ cells was measured before and after activation of PBMC with antiCD3 and anti-CD28 antibody-conjugated microbeads (Supplementary Table S5). As displayed in Figure 2B, CD2 
expression is significantly elevated after activation on $\mathrm{T}$ cells $(\mathrm{p}=0.0034), \mathrm{CD}^{\mathrm{dim}} \mathrm{NK}$ cells $(\mathrm{p}=0.0024), \mathrm{CD}^{\mathrm{d}} 6^{\text {bright }} \mathrm{NK}$ cells $(\mathrm{p}=0.017)$ and $\mathrm{CD}^{-} 6^{-} \mathrm{CD}^{+} 6^{+} \mathrm{NK}$ cells $(\mathrm{p}=0.0029$; two-tailed paired t-test).

As shown in Figure 3, almost all NK cells (91.0\%) expressed Fc $\gamma$ RIIIA (CD16) while FcyRII expression was heterogeneous (19.2\%, CD32). NK cells did not express Fc $\gamma$ RI (data not shown).

\section{Effect of CD2 Blockade on Antibody- Mediated and Natural NK Cell Activation in Autologous and Mixed Lymphocyte Culture}

To investigate the effect of siplizumab on NK cell activation, autologous lymphocyte culture (ALC) and MLR were performed with a saturating dose of siplizumab. As shown in Figure 4, siplizumab significantly increased the percentage of CD69+ NK
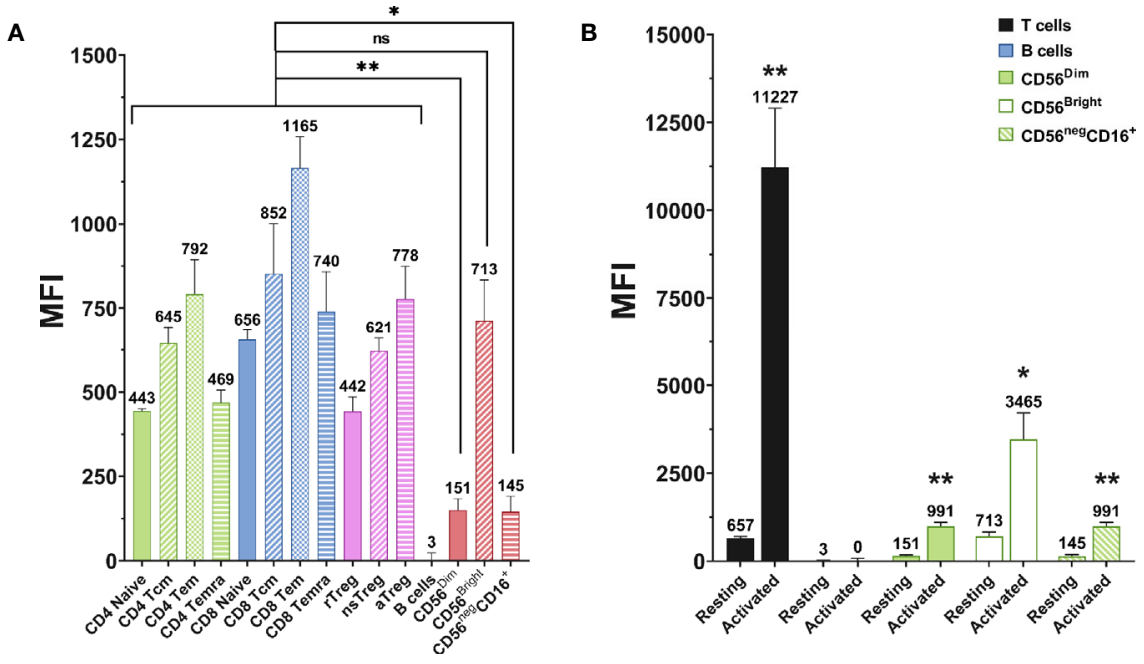

FIGURE 2 | CD2 expression on different lymphocyte (sub-)populations. Data displayed as average median fluorescence intensity $\pm S E M\left(n=5\right.$; ${ }^{*} p<0.05$, ${ }^{* *} \mathrm{p}<0.01$ ). (A) CD2 expression on different T and NK cell subpopulations. CD56 bright $N K$ cells express CD2 at levels comparable to that of T cells. In contrast, CD56 ${ }^{\text {dim }}$, and CD56 ${ }^{\text {neg }} \mathrm{NK}$ cells express significantly lower levels of CD2 ( $\mathrm{p}=0.0074$ and $\mathrm{p}=0.0111$, respectively, repeated-measure one-way ANOVA followed by Dunnett's multiple comparison test). (B) CD2 expression on resting and activated lymphocyte populations. CD2 expression was markedly upregulated after activation on T cells ( $(p=0.0034)$, CD56 dim NK cells $(p=0.0024)$, CD56 bright NK cells $(p=0.017)$, and CD56 $6^{\text {neg }} C^{\text {d } 16} 6^{+}$NK cells $(0.0029)$. No difference was observed on B Cells (two-tailed paired t-test).

A

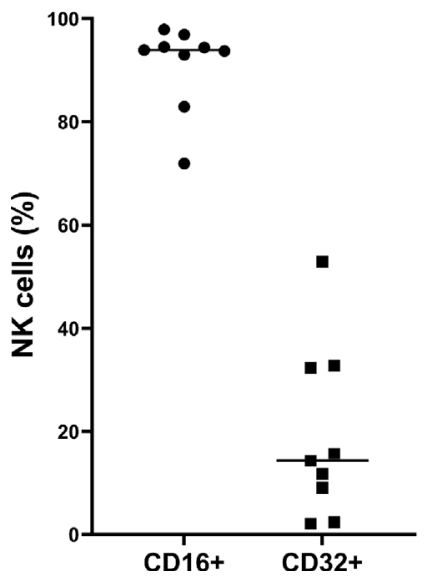

B
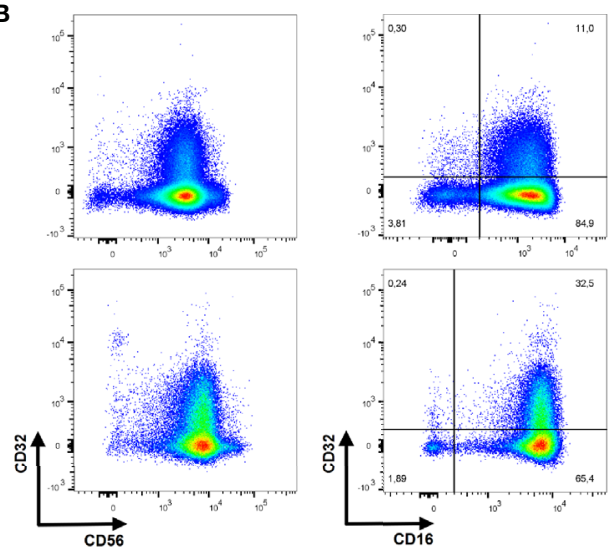

FIGURE 3 | Expression of Fc gamma receptor (FcyR) II (CD32) and FcyRIII (CD16) on NK cells. (A) On average 91.0\% of NK cells express FcyRIII while 19.2\% express FcyRll $(n=9)$. Mean shown as horizontal line. (B) Representative plots of FcyRll and FcyRlll expression on NK cells (CD3 ${ }^{-} \mathrm{CD}^{+} 6^{+}$and/or $\mathrm{CD}^{1} 6^{+}$lymphocytes), Upper: Representative plots of NK cells from donor with relatively low CD32 expression. Lower: Representative plots of NK cells from donor with relatively high CD32 expression. 
A

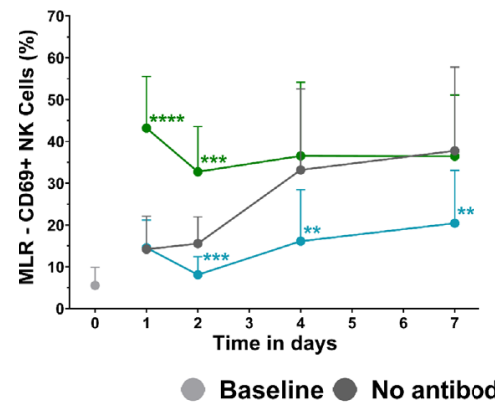

B

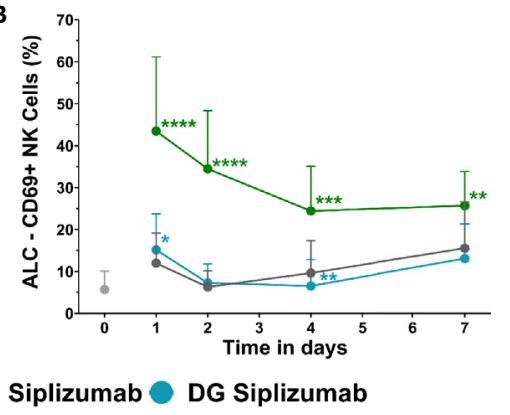

FIGURE 4 | CD69 Expression on NK cells in mixed lymphocyte reaction (MLR) and autologous lymphocyte culture (ALC) over time. CD69 Expression without addition of antibody (No antibody) and with added antibody was assessed at baseline (day 0) and after one, two, four and 7 days via flow cytometry. Significance testing was conducted via two-way ANOVA with untreated controls (no antibody) serving as the comparison data set $\left({ }^{\star} p<0.05,{ }^{* *} p<0.01,{ }^{* \star *} p<0.001,{ }^{* \star \star *} p<\right.$ 0.0001). Siplizumab and deglycosylated (DG) siplizumab were used at $10 \mu \mathrm{g} / \mathrm{ml}$, a dose which has previously determined to saturate target antigen over 7 days. Data displayed as mean \pm SD ( $n=12$ ). (A) Percentage of $C D 69^{+}$NK cells in MLR over time. (B) Percentage of CD69+ NK cells in ALC over time.

cells (\% CD69 ${ }^{+} \mathrm{NK}$ cells) after $1(\mathrm{p}<0.0001)$ and $2(\mathrm{p}=0.0001)$ days of MLR as well as after 1 ( $\mathrm{p}<0.0001), 2(\mathrm{p}<0.0001), 4(\mathrm{p}=0.0006)$, and 7 days $(\mathrm{p}=0.0082)$ of ALC (Supplementary Tables S6 and S7). On days 4 and 7 of MLR an increase in \% CD69 ${ }^{+} \mathrm{NK}$ cells in untreated controls (no antibody) was observed. This likely derived from NK cells reacting against allogeneic HLA and/or absence of self-HLA on PBMC from the other donor. As shown in Figure 4, DG siplizumab significantly reduced \% CD69+ NK cells after 4 $(\mathrm{p}=0.0012)$ and $7(\mathrm{p}=0.0035)$ days (Repeated-measure two-way ANOVA followed by Dunnett's multiple comparison test). Addition of DG siplizumab did not meaningfully change the percentage of $\mathrm{CD} 9^{+} \mathrm{NK}$ cells in ALC.
To further characterize the inhibition of NK cell activation in MLR by CD2 blockade, dose titrations from 0.0001 to $10 \mu \mathrm{g} / \mathrm{ml}$ were performed and CD69 expression on NK cells was analyzed after 7 days of MLR. MLRs were incubated with siplizumab, DG siplizumab, FcS anti-CD2 IgG1, FcS anti-CD2 IgG2, or FcS antiCD2 IgG4. As displayed in Figure 5A, doses of siplizumab induced a significant increase in $\% \mathrm{CD}^{+} 9^{+} \mathrm{NK}$ cells at $0.1 \mu \mathrm{g} / \mathrm{ml}(\mathrm{p}=0.0003)$, $1 \mu \mathrm{g} / \mathrm{ml}(\mathrm{p}=0.0018)$, and $10 \mu \mathrm{g} / \mathrm{ml}(\mathrm{p}=0.0256)$ relative to untreated controls (No antibody). In contrast, DG siplizumab induced a significant decrease of $\% \mathrm{CD}^{+} 9^{+} \mathrm{NK}$ cells at $1 \mu \mathrm{g} / \mathrm{ml}(\mathrm{p}=0.0012)$ and $10 \mu \mathrm{g} / \mathrm{ml}(\mathrm{p}=0.006)$. FcS anti-CD2 IgG1, FcS anti-CD2 IgG2, and $\mathrm{FcS}$ anti-CD2 IgG4 significantly reduced $\% \mathrm{CD} 9^{+} \mathrm{NK}$ cells at
A

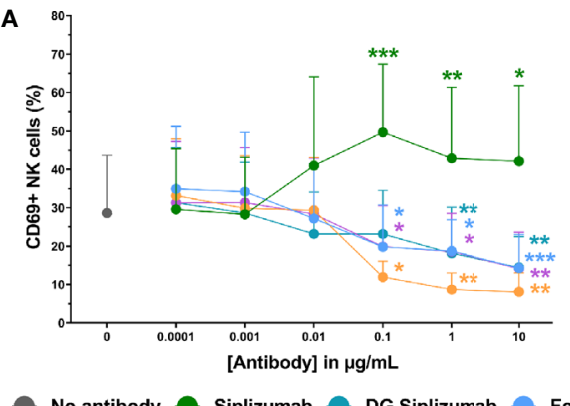

C

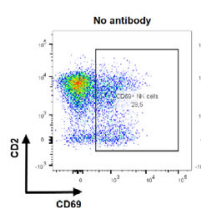

B

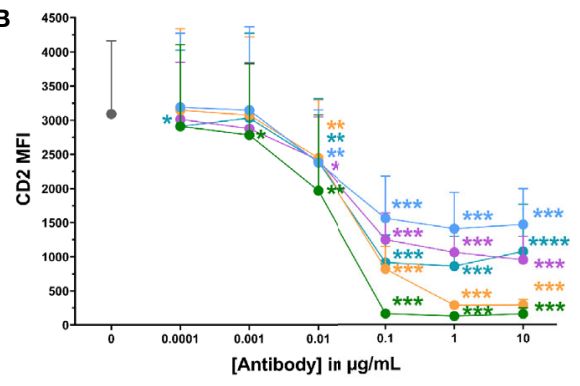

anti-CD2 IgG1 FcS anti-CD2 IgG2 FcS anti-CD2 IgG4
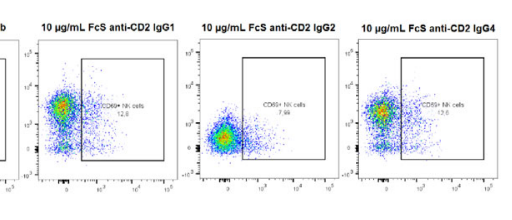

FIGURE 5 | CD69 and CD2 expression on NK cells after 7 days of mixed lymphocyte reaction. Significance testing was conducted via one-way ANOVA with untreated controls (no antibody) serving as the comparison data set ( ${ }^{\star} \mathrm{p}<0.05,{ }^{\star \star} \mathrm{p}<0.01,{ }^{\star \star \star} \mathrm{p}<0.001$, ${ }^{\star \star \star *} \mathrm{p}<0.0001$ ). Siplizumab, deglycosylated (DG)

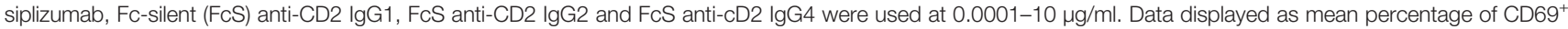
NK cells \pm SD (A) or average median CD2 fluorescence intensity + SD [CD2 MFI, (B); $n=9)$. (C) Representative dot plots of CD2 and CD69 expression on NK cells in untreated controls (no antibody) or $10 \mu \mathrm{g} / \mathrm{ml}$ anti-CD2. 
$0.1 \mu \mathrm{g} / \mathrm{ml}(\mathrm{p}=0.0178, \mathrm{p}=0.0122, \mathrm{p}=0.0234$, respectively), $1 \mu \mathrm{g} / \mathrm{ml}$ $(\mathrm{p}=0.0311, \mathrm{p}=0.0039, \mathrm{p}=0.0388$, respectively), and $10 \mu \mathrm{g} / \mathrm{ml}$ ( $\mathrm{p}=0.0008, \mathrm{p}=0.0027, \mathrm{p}=0.0023$, respectively) (Repeated-measure one-way ANOVA followed by Dunnett's multiple comparison test; Supplementary Table S8).

Additionally, median CD2 fluorescence intensity (CD2 MFI) on NK cells was measured to assess if siplizumab or FcS antiCD2 mAbs affect CD2 expression (Figures 2B, C). Siplizumab induced a significant decrease of CD2 MFI on NK cells at $0.001-$ $10 \mu \mathrm{g} / \mathrm{ml}$ ( $\mathrm{p} \leq 0.0354$ ) relative to untreated controls. Varying degrees of significant CD2 downregulation were observed with DG siplizumab ( $\mathrm{p} \leq 0.0064), \mathrm{FcS}$ anti-CD2 $\operatorname{IgG} 1(\mathrm{p} \leq 0.0050)$, $\mathrm{FcS}$ anti-CD2 IgG2 (p $\leq 0.0091)$, and FcS anti-CD2 IgG4 (p $\leq$ 0.0142 ) at $0.01-10 \mu \mathrm{g} / \mathrm{ml}$ (Repeated-measure one-way ANOVA followed by Dunnett's multiple comparison test; Supplementary Table S9).

\section{NK Fratricide}

To test whether siplizumab can induce NK cell fratricide, purified NK cells were cultured in the presence of increasing doses of siplizumab or Fc-silent anti-CD2 mAbs. As shown in Figure 6, siplizumab significantly increased NK cell lysis in purified NK cell culture at $0.01-10 \mu \mathrm{g} / \mathrm{ml}(\mathrm{p} \leq 0.0018)$ relative to untreated controls. Furthermore, siplizumab induced a significant dose-dependent depletion of total NK cells ( $\mathrm{p} \leq$ 0.0301), CD56dim NK cells $(\mathrm{p} \leq 0.0191)$ and CD56bright NK cells $(p \leq 0.0093)$ at $0.01-10 \mu \mathrm{g} / \mathrm{ml}$ when compared to untreated controls. In contrast, FcS anti-CD2 mAbs did not induce dosedependent NK cell lysis or depletion in pure NK culture, except
FcS anti-CD2 IgG2 which induced a mild but statistically significant depletion of CD56bright NK cells at $0.1-10 \mu \mathrm{g} / \mathrm{ml}$ ( $\mathrm{p} \leq$ 0.0132; Repeated-measure one-way ANOVA followed by Dunnett's multiple comparison test; Supplementary Tables S10-S13).

Additionally, Figure 7 shows that siplizumab induced a significant dose-dependent increase in NK cell degranulation ( $\mathrm{p} \leq 0.0114 ; \mathrm{CD} 107 \mathrm{a}^{+} \mathrm{NK}$ cells) and a strong decrease of CD16 expression on NK cells ( $\mathrm{p} \leq 0.0022$ ), indicative of ADCC. No FcS anti-CD2 mAb induced degranulation and only FcS anti-CD2 IgG2 induced a minor but statistically significant decrease in CD16 MFI at $0.1-1 \mu \mathrm{g} / \mathrm{ml}$ ( $\mathrm{p} \leq 0.0269$; Repeated-measure oneway ANOVA followed by Dunnett's multiple comparison test; Supplementary Tables S14 and S15).

\section{Natural NK Cytotoxicity}

To test the effect of CD2 blockade on natural cytotoxicity, purified NK cells were incubated with titrated doses of siplizumab or FcS anti-CD2 $\mathrm{mAb}$ in the presence of SPI-801 target cells (HLA).

As shown in Figure 8, CD2 blockade with FcS anti-CD2 mAb did not significantly inhibit NK cell degranulation in response to SPI-801 target cells, irrespective of whether pre-incubation of NK cells with FcS anti-CD2 mAb lasted 30 min or 2 days prior to target cell addition. After $30 \mathrm{~min}$ of pre-incubation, siplizumab significantly increased NK cell degranulation at $0.1-10 \mu \mathrm{g} / \mathrm{ml}$ ( $\mathrm{p} \leq 0.0482$ ) but not after 2 days of pre-incubation (Repeatedmeasure one-way ANOVA followed by Dunnett's multiple comparison test; Supplementary Tables S16 and S17). CD2
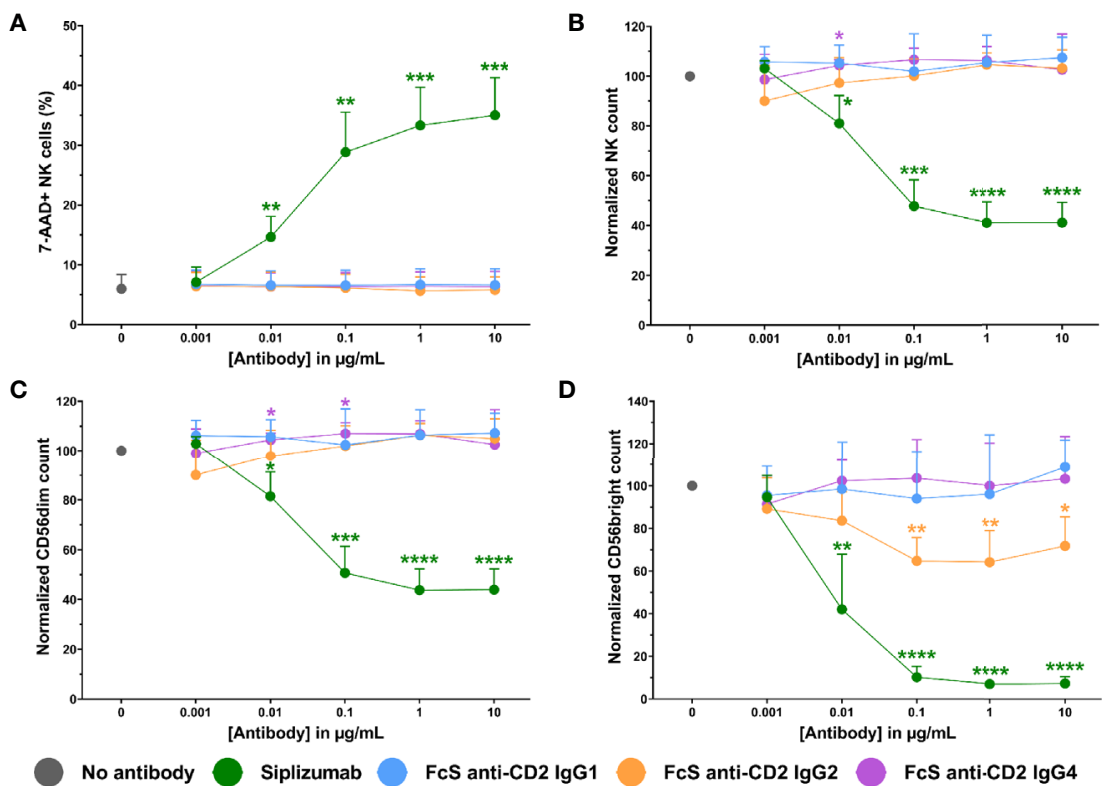

FIGURE 6 | NK cell fratricide. Purified NK cells were incubated with no antibody, 0.001-10 $\mu \mathrm{g} / \mathrm{ml}$ Siplizumab or 0.001-10 $\mu \mathrm{g} / \mathrm{ml}$ Fc-silent (FcS) anti-CD2 lgG antibodies overnight. Significance testing was conducted via one-way ANOVA with untreated controls (no antibody) serving as the comparison data set (N=6; $\left.{ }^{*} \mathrm{p}<0.05,{ }^{* \star} \mathrm{p}<0.01,{ }^{\star \star \star} \mathrm{p}<0.001,{ }^{* \star \star *} \mathrm{p}<0.0001\right)$. (A) NK cell lysis. Mean percentage of 7-AAD+ NK cells $+\mathrm{SD}$. (B) NK cell count. Mean normalized NK cell count +SD. (C) CD56 ${ }^{\text {dim }} \mathrm{NK}$ cell count. Mean normalized CD56 ${ }^{\text {dim }} \mathrm{NK}$ cell count +SD. (D) CD56 ${ }^{\text {bright }} \mathrm{NK}$ cell count. Mean normalized CD56 bright $\mathrm{NK}$ cell count + SD. 

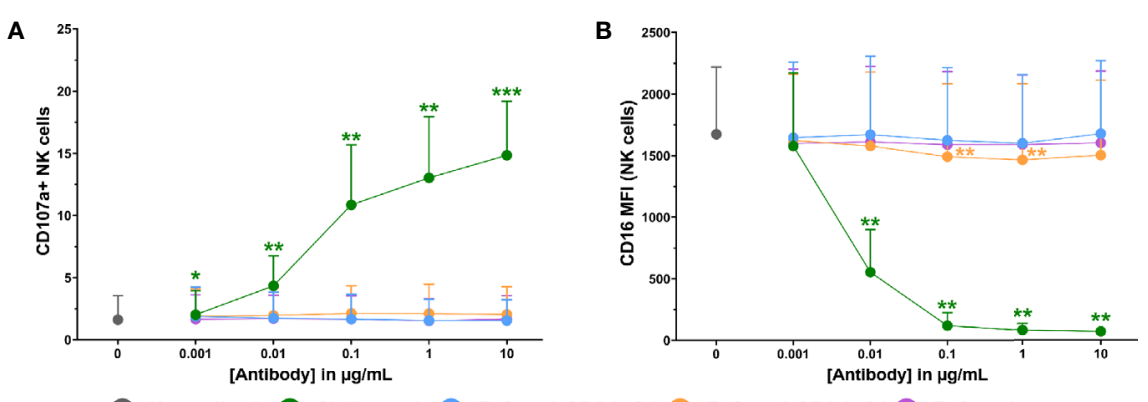

No antibody Siplizumab $\bigcirc$ FcS anti-CD2 IgG1 FcS anti-CD2 IgG2 FcS anti-CD2 IgG4

C
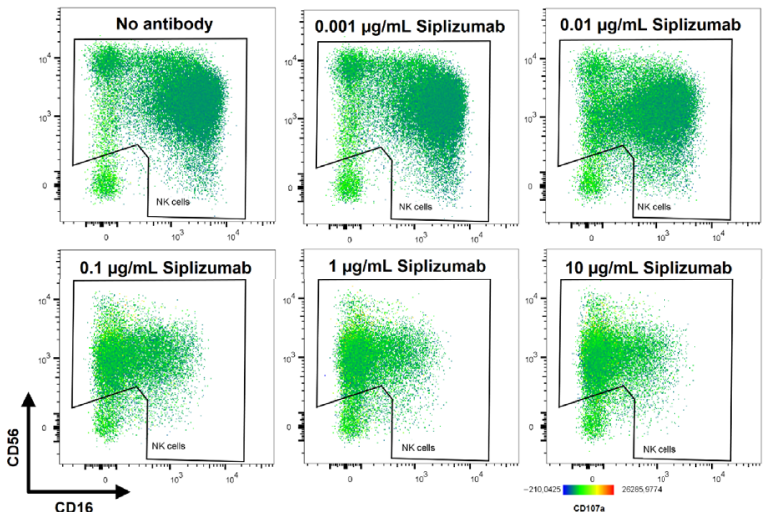

FIGURE 7 | NK cell degranulation and ADCC in purified NK cell culture. Purified NK cells were incubated without antibody, with 0.001-10 $\mu$ g/ml Siplizumab or $0.001-10 \mu \mathrm{g} / \mathrm{ml} \mathrm{FC}$-silent (FcS) anti-CD2 lgG antibodies. Significance testing was conducted via one-way ANOVA with untreated controls (no antibody) serving as the comparison data set $\left(\mathrm{N}=6\right.$; $\left.{ }^{*} \mathrm{p}<0.05,{ }^{\star \star} \mathrm{p}<0.01,{ }^{\star \star *} \mathrm{p}<0.001\right)$. (A) NK cell degranulation. Mean percentage of CD107a+ NK cells $+\mathrm{SD}$. (B) CD16 expression on NK cells. Average median CD16 fluorescence intensity +SD on NK cells. (C) Representative heatmap dot plots illustrating CD16 downregulation and NK cell degranulation with increasing doses of Siplizumab in purified NK cell culture.

blockade did not induce any change in SPI-801 count (data not shown).

\section{Antibody-Dependent Cytotoxicity}

To test whether CD2 blockade influences ADCC, purified NK cells were pre-incubated with siplizumab or FcS anti-CD2 mAb before addition of titrated doses of Rituximab and CD20 ${ }^{+}$target cells (Daudi). As shown in Figures 9A, B, CD2 blockade with FcS anti-CD2 mAb did not significantly affect NK cell degranulation or target cell killing in response to increasing doses of Rituximab (Supplementary Tables S18 and S19). As displayed in Figure 9C, Rituximab induced a significant increase of CD2 expression on NK cells at $0.01-1 \mu \mathrm{g} / \mathrm{ml}(\mathrm{p} \leq$ 0.0248; Repeated-measure one-way ANOVA followed by Dunnett's multiple comparison test; Supplementary Table S20). While anti-CD2 mAbs induced different degrees of CD2 downregulation in this setting, this did not seem to affect ADCC.

\section{DISCUSSION}

The present study has demonstrated that siplizumab can induce NK cell fratricide through ADCC and that CD2 binding by siplizumab does not induce NK cell activation. Further, it was shown that blockade of CD2 with Fc-silent anti-CD2 mAb inhibits CD69 expression on NK cells in MLR. While these results suggested a potential inhibitory effect of CD2 blockade on natural cytotoxicity in MLR, no inhibition of natural cytotoxicity was detected in experiments using purified NK cells. Further, while siplizumab induces ADCC through CD16, this study showed that CD2 blockade by siplizumab does not inhibit ADCC. It should be noted that siplizumab was included in assays evaluating the effect of CD2 blockade on Rituximabinduced ADCC and natural cytotoxicity for completeness, however, NK cell fratricide makes results seen with siplizumab in these assays difficult to interpret.

Limitations of this study included the exclusive use of peripheral blood NK cells which often display different functional profiles and phenotypes when compared to tissue NK cells (18-21). Moreover, all anti-CD2 antibodies used in this study bind the same CD2 epitope [situated near T11.2 and T11.3 in the extracellular domain of CD2 (22)]. Thus, it remains to be determined whether different effects may be induced upon blockade of alternative CD2 epitopes, e.g. in the region binding to LFA3. The data presented in this study had a limited sample size, meaning that it may not necessarily be representative of the average across a broader population. 

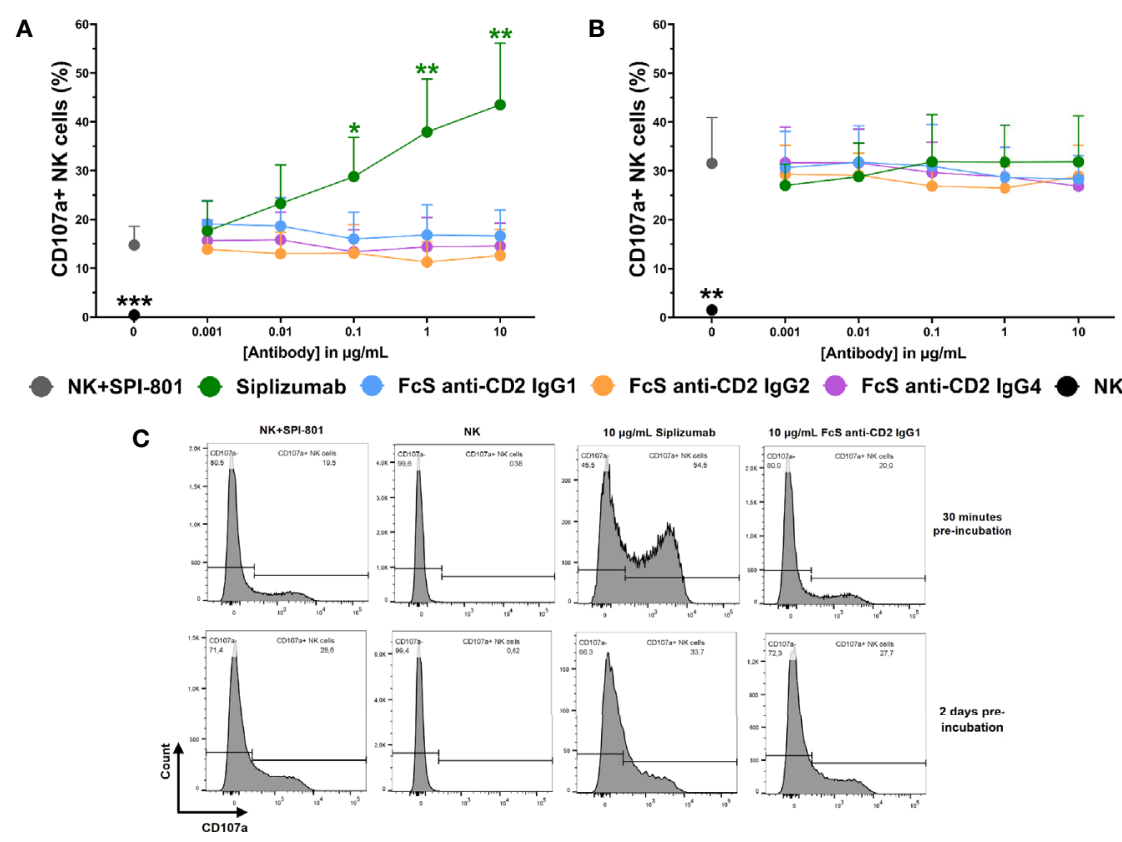

FIGURE 8 | Natural NK cell cytotoxicity. Purified NK cells were pre-incubated without antibody, with $0.001-10 \mu \mathrm{g} / \mathrm{ml}$ Siplizumab or $0.001-10 \mu \mathrm{g} / \mathrm{ml}$ Fc-silent (FcS) anti-CD2 lgG antibodies for $30 \mathrm{~min}$ (A) or 2 days (B) followed by addition of HLA class I' target cells (SPI-801). Significance testing was conducted via one-way ANOVA with untreated controls (no antibody) serving as the comparison data set $\left(\mathrm{N}=6 ;{ }^{*} \mathrm{p}<0.05,{ }^{* *} \mathrm{p}<0.01,{ }^{* \star *} \mathrm{p}<0.001\right)$. (C) Representative histograms of NK cell degranulation in response to HLA class $I^{-}$target cells without addition of antibody (NK+SPI-801), without addition of antibody and HLA class I' target cells (NK) or in the presence of Siplizumab/FcS anti-CD2 lgG1.

Previous evidence points towards an important role of $\mathrm{CD} 2$ in natural NK cell cytotoxicity. NK cells of patients homozygous for a mutation of L66 in CD16 (L66H) display impaired natural cytotoxicity but normal ADCC $(11,23)$. This seemed to result from recruitment of $\mathrm{CD} 16$ to the NK cell immunological synapse (NKIS) by CD2. Even though IgG antibodies are not involved in natural cytotoxicity, CD16 is recruited to the NKIS, potentially to achieve an enrichment of agonistic receptors in this region. Interestingly, NK cells expressing L66H CD16 displayed lower $\mathrm{CD} 2$ expression levels than NK cells expressing wild-type CD16 (11). Additionally, evidence indicates an important role of CD2 in nanotube formation between NK cells and target cells during natural cytotoxicity (24). Further, similar to T cells CD2 seems to mainly assume a peripheral positioning in the NKIS (24) and induces signaling through similar pathways as those observed in T cells (25-27). Surprisingly, no inhibition of natural cytotoxicity resulting from CD2 blockade was detected in this study. This study only used one target cell type (SPI-801) for assessment of natural cytotoxicity and future research should investigate whether CD2 blockade affects natural cytotoxicity against target cells requiring co-expression of $\mathrm{CD} 2$ and $\mathrm{CD} 16$ for induction of natural cytotoxicity like mel1106.

The relevance of observed CD69 downregulation on NK cells in MLR upon addition of FcS anti-CD2 antibodies remains unclear. While $\mathrm{CD} 2$ blockade could not be shown to inhibit ADCC or natural cytotoxicity, CD2-LFA3 interaction may be important for other immunological processes like crosstalk between NK cells and dendritic cells (28) or natural cytotoxicity against target cells requiring co-expression of $\mathrm{CD} 16$ and $\mathrm{CD} 2$ on effector cells for induction of a cytotoxic response.

Previous clinical trials of CD2-targeting therapies were predominantly conducted with two agents: (1) Alefacept, a fusion protein of an IgG1 $\mathrm{Fc}$ fragment and the CD2-binding domain of LFA3 and (2) siplizumab. Both agents are depletory, i.e. their mechanism of action is mediated by both $\mathrm{CD} 2$ blockade and FcyR-mediated depletion. Previous studies have detected an initial pro-inflammatory effect of Alefacept treatment in psoriasis patients (29). Recently published evidence indicates no activation effect of siplizumab on T cells in MLR (3) and this study showed that CD2 ligation by siplizumab does not have an inherent activating effect on NK cells. Thus, siplizumab may be a more desirable therapeutic agent for CD2-targeting as it does not exert an agonistic effect upon CD2 binding. Nevertheless, even though CD2 ligation by siplizumab does not induce NK cell activation, siplizumab-mediated ADCC still induces NK cell activation and thus may increase pro-inflammatory signaling by NK cells.

A number of transplantation and autoimmune conditions feature undesired NK cell activation and cytotoxicity. In solid organ transplantation, a large number of cells expressing foreign human leukocyte antigens (HLA) are introduced into the transplant recipient. Mouse models have shown that alloreactive NK cells can be a notable contributor to kidney allograft rejection (30). Further, alloreactive NK cells seemed to contribute allograft 


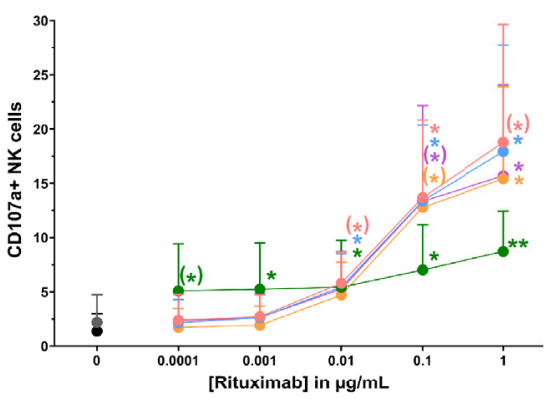

B

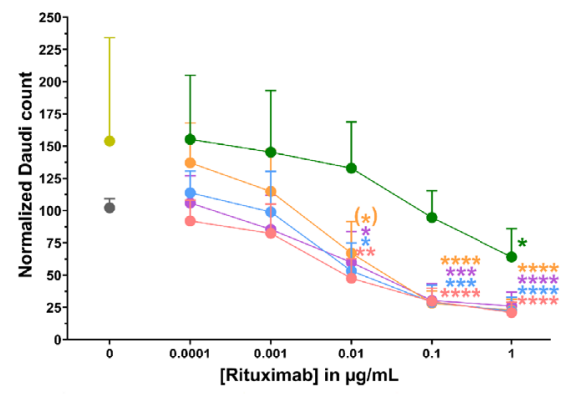

C

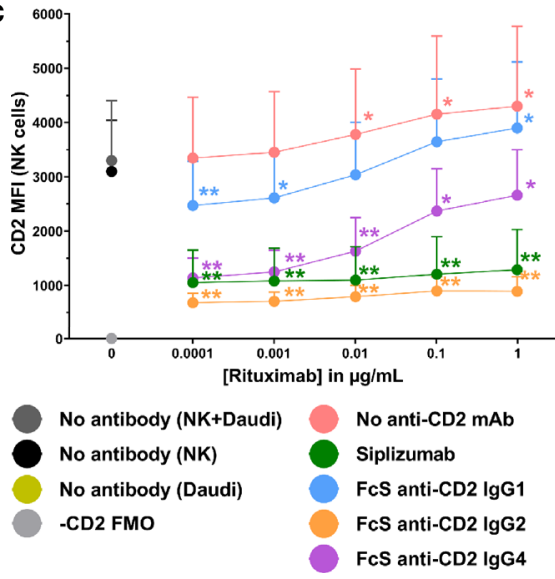

D

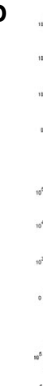

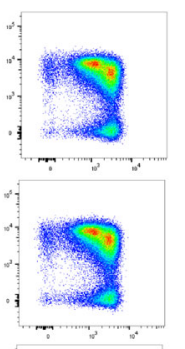

"1.

(1)

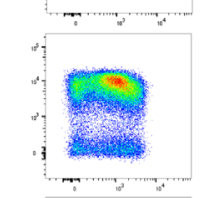

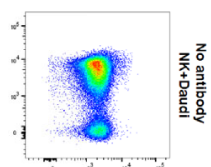

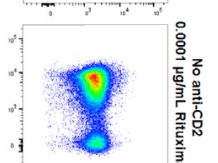

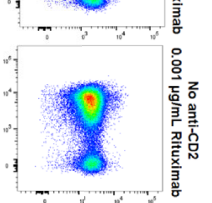

(.)

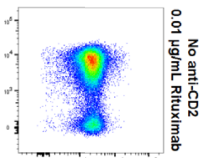

$\rightarrow+3 a^{2}$
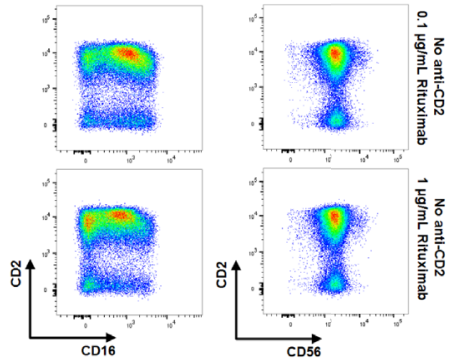

\section{8}

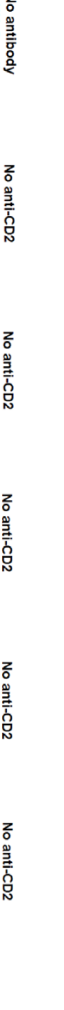

FIGURE 9 | Antibody-dependent cytotoxicity. Purified NK cells were pre-incubated without antibody or with saturating doses of Siplizumab/Fc-silent (FcS) anti-CD2 IgG antibodies before addition of titrated doses of Rituximab and CD20 ${ }^{+}$target cells (Daudi). Significance testing was conducted via one-way ANOVA with untreated controls (no antibody) serving as the comparison data set $\left(\mathrm{N}=6\right.$; ${ }^{(*)} \mathrm{p}<0.1,{ }^{*} \mathrm{p}<0.05,{ }^{* *} \mathrm{p}<0.01,{ }^{* \star *} \mathrm{p}<0.001$, $\left.{ }^{* \star *} \mathrm{p}<0.0001\right)$. (A) NK cell degranulation. Mean percentage of CD107a ${ }^{+}$NK cells + SD. (B) Target cell depletion. Mean normalized target cell count + SD (C) CD2 expression. Average median CD2 fluorescence intensity +SD on NK cells. (D) Representative dot plots illustrating increased CD2 expression on NK cells resulting ADCC induction.

rejection in human liver transplantation (31). While this study did not show an inhibition of natural NK cell cytotoxicity by CD2 blockade, depletion of activated NK cells using siplizumab may be a viable treatment modality in conditions where NK cells and T cells are disease-mediating. Addition of siplizumab to commonly used immunosuppressants in transplantation may be desirable since standard immunosuppression inhibits NK cell alloreactivity heterogeneously (32). In autoimmune conditions like rheumatoid arthritis (RA), NK cell count in peripheral blood decreases. In contrast, an increased frequency of NK cells was observed in the synovial fluid of RA patients. Similarly, enrichment of NK cells in tissues affected by autoimmune disease has also been observed in diabetes and psoriasis patients $(33,34)$. Notably, NK cells in synovial fluid of RA patients are predominantly CD56 $6^{\text {bright }}$, an NK cell subpopulation characterized by high cytokine secretion potential (35) and relatively high CD2 expression levels. Depletion of cells expressing high CD2 levels in autoimmune conditions involving $\mathrm{NK}$ cell migration into affected tissues may decrease NK cell tissue infiltration and related cytokine release into tissue microenvironment. Given the high cytokine secretion potential of CD $56^{\text {bright }} \mathrm{NK}$ cells, depletion of CD2 $2^{\text {high }}$ cells may lower inflammation levels in tissues affected by autoimmune disease.

In addition to ADCC, siplizumab may also induce depletion via antibody-dependent cell phagocytosis as a result of CD32 and CD64 binding. Indeed, ADCP-mediated depletion by siplizumab 
may be underestimated when considering MLR results due the absence of mature phagocytes among PBMC. Interestingly, animal models using other CD2 antibodies (36) or depletory anti-CD20 mAbs (37) have shown accumulation of depleted cells in the liver which contains an abundance of FcyR-bearing cells including hepatic phagocytes.

In conclusion, siplizumab induces NK cell activation and NK cell fratricide through Fc $\gamma$ RIIIA-mediated induction of ADCC but not through CD2 ligation. Further, this study found no effect of $\mathrm{CD} 2$ blockade by siplizumab on natural cytotoxicity or ADCC induction.

\section{DATA AVAILABILITY STATEMENT}

The raw data supporting the conclusions of this article will be made available by the authors, without undue reservation.

\section{REFERENCES}

1. Binder C, Cvetkovski F, Sellberg F, Berg S, Visbal HP, Sachs DH, et al. CD2 Immunobiology. Front Immunol (2020) 11:1090. doi: 10.3389/fimmu.2020. 01090

2. Podestà MA, Binder C, Sellberg F, DeWolf S, Shonts B, Ho S-H, et al. Siplizumab selectively depletes effector memory $\mathrm{T}$ cells and promotes a relative expansion of alloreactive regulatory $\mathrm{T}$ cells in vitro. Am J Transplant Off J Am Soc Transplant Am Soc Transpl Surg (2020) 20:88-100. doi: 10.1111/ajt.15533

3. Binder C, Sellberg F, Cvetkovski F, Berglund E, Berglund D. Siplizumab, an anti$\mathrm{CD} 2$ monoclonal antibody, induces a unique set of immune modulatory effects compared to Alemtuzumab, rabbit Anti-Thymocyte Globulin and Basiliximab in vitro. Front Immunol (2020) 11:592553. doi: 10.3389/fimmu.2020.592553

4. Sellberg F, Berglund D, Binder C, Hope J, Fontenot J, Griesemer A, et al. Pharmacokinetic and pharmacodynamic study of a clinically effective antiCD2 monoclonal antibody. Scand J Immunol (2020) 91:e12839. doi: 10.1111/ sji.12839

5. O'Mahony D, Morris JC, Stetler-Stevenson M, Matthews H, Pittaluga S, Albert P, et al. EBV-Related Lymphoproliferative Disease Complicating Therapy with Siplizumab, a Novel Anti-CD2 Mediated T- and NK-Cell Depleting Agent, in Patients with T-Cell Malignancies. Blood (2007) 110:3565-5. doi: 10.1182/blood.V110.11.3565.3565

6. Branco L, Barren P, Mao SY, Pfarr D. Selective deletion of antigen-specific, activated $\mathrm{T}$ cells by a humanized mab to $\mathrm{CD} 2$ (medi-507) is mediated by NK cells. TRANSPLANTATION (1999) 68:1588-96. doi: 10.1097/00007890199911270-00026

7. Watzl C. How to trigger a killer: modulation of natural killer cell reactivity on many levels. Adv Immunol (2014) 124:137-70. doi: 10.1016/B978-0-12800147-9.00005-4

8. Paul S, Lal G. The Molecular Mechanism of Natural Killer Cells Function and Its Importance in Cancer Immunotherapy. Front Immunol (2017) 8:1124. doi: 10.3389/fimmu.2017.01124

9. Dutertre C-A, Bonnin-Gélizé E, Pulford K, Bourel D, Fridman W-H, Teillaud J-L. A novel subset of NK cells expressing high levels of inhibitory FcgammaRIIB modulating antibody-dependent function. J Leukoc Biol (2008) 84:1511-20. doi: 10.1189/jlb.0608343

10. Orange JS, Harris KE, Andzelm MM, Valter MM, Geha RS, Strominger JL. The mature activating natural killer cell immunologic synapse is formed in distinct stages. Proc Natl Acad Sci USA (2003) 100:14151. doi: 10.1073/pnas. 1835830100

11. Grier JT, Forbes LR, Monaco-Shawver L, Oshinsky J, Atkinson TP, Moody C, et al. Human immunodeficiency-causing mutation defines CD16 in spontaneous NK cell cytotoxicity. J Clin Invest (2012) 122:3769-80. doi: $10.1172 / \mathrm{JCI} 64837$

\section{AUTHOR CONTRIBUTIONS}

$\mathrm{CB}, \mathrm{FS}$, and FC carried out experiments and wrote the first manuscript. All authors contributed to the article and approved the submitted version.

\section{ACKNOWLEDGMENTS}

The authors would like to thank Dr. David H. Sachs for helpful review of the manuscript.

\section{SUPPLEMENTARY MATERIAL}

The Supplementary Material for this article can be found online at: https://www.frontiersin.org/articles/10.3389/fimmu.2021. 599526/full\#supplementary-material

12. Demetriou P, Abu-Shah E, Valvo S, McCuaig S, Mayya V, Kvalvaag A, et al. A dynamic CD2-rich compartment at the outer edge of the immunological synapse boosts and integrates signals. Nat Immunol (2020) 21:1232-43. doi: 10.1038/s41590-020-0770-X

13. Arduin E, Arora S, Bamert PR, Kuiper T, Popp S, Geisse S, et al. Highly reduced binding to high and low affinity mouse Fc gamma receptors by L234A/L235A and N297A Fc mutations engineered into mouse IgG2a. Mol Immunol (2015) 63:456-63. doi: 10.1016/j.molimm.2014.09.017

14. Lo DJ, Weaver TA, Stempora L, Mehta AK, Ford ML, Larsen CP, et al. Selective targeting of human alloresponsive CD8 effector memory $\mathrm{T}$ cells based on CD2 expression. Am J Transplant Off J Am Soc Transplant Am Soc Transpl Surg (2011) 11:22. doi: 10.1111/j.1600-6143.2010.03317.x

15. Wang X, Mathieu M, Brezski RJ. IgG Fc engineering to modulate antibody effector functions. Protein Cell (2018) 9:63-73. doi: 10.1007/s13238-0170473-8

16. Silva J-P, Vetterlein O, Jose J, Peters S, Kirby H. The S228P mutation prevents in vivo and in vitro IgG4 Fab-arm exchange as demonstrated using a combination of novel quantitative immunoassays and physiological matrix preparation. J Biol Chem (2015) 290:5462-9. doi: 10.1074/jbc.M114.600973

17. Schlothauer T, Herter S, Koller CF, Grau-Richards S, Steinhart V, Spick C, et al. Novel human IgG1 and IgG4 FC-engineered antibodies with completely abolished immune effector functions. Protein Eng Des Sel (2016) 29:457-66. doi: 10.1093/protein/gzw040

18. Harmon C, Sanchez-Fueyo A, O'Farrelly C, Houlihan DD. Natural Killer Cells and Liver Transplantation: Orchestrators of Rejection or Tolerance? Am J Transplant Off J Am Soc Transplant Am Soc Transpl Surg (2016) 16:751-7. doi: 10.1111/ajt.13565

19. Marquardt N, Kekäläinen E, Chen P, Kvedaraite E, Wilson JN, Ivarsson MA, et al. Human lung natural killer cells are predominantly comprised of highly differentiated hypofunctional CD69-CD56dim cells. J Allergy Clin Immunol (2017) 139:1321-30. doi: 10.1016/j.jaci.2016.07.043

20. Marquardt N, Kekäläinen E, Chen P, Lourda M, Wilson JN, Scharenberg M, et al. Unique transcriptional and protein-expression signature in human lung tissue-resident NK cells. Nat Commun (2019) 10:3841. doi: 10.1038/s41467019-11632-9

21. Mikulak J, Bruni E, Oriolo F, Di Vito C, Mavilio D. Hepatic Natural Killer Cells: Organ-Specific Sentinels of Liver Immune Homeostasis and Physiopathology. Front Immunol (2019) 10:946. doi: 10.3389/fimmu.2019. 00946

22. Damschroder MM, Kozhich AA, Woods RM, Cheng L, Mullikin BA, Wilson $\mathrm{SD}$, et al. Analysis of human and primate CD2 molecules by protein sequence and epitope mapping with anti-human CD2 antibodies. Mol Immunol (2004) 41:985-1000. doi: 10.1016/j.molimm.2004.05.004

23. Jawahar S, Moody C, Chan M, Finberg R, Geha R, Chatila T. Natural Killer (NK) cell deficiency associated with an epitope-deficient Fc receptor type IIIA 
(CD16-II). Clin Exp Immunol (1996) 103:408-13. doi: 10.1111/j.13652249.1996.tb08295.x

24. Comerci CJ, Mace EM, Banerjee PP, Orange JS. CD2 promotes human natural killer cell membrane nanotube formation. PloS One (2012) 7:e47664. doi: 10.1371/journal.pone.0047664

25. Umehara H, Huang JY, Kono T, Tabassam FH, Okazaki T, Bloom ET, et al. Involvement of protein tyrosine kinase p72syk and phosphatidylinositol 3kinase in CD2-mediated granular exocytosis in the natural killer cell line, NK3.3. J Immunol Baltim Md 1950 (1997) 159:1200-7.

26. Umehara H, Inoue H, Huang J, Kono T, Minami Y, Tanaka Y, et al. Role for adapter proteins in costimulatory signals of $\mathrm{CD} 2$ and IL-2 on NK cell activation. Mol Immunol (2002) 38:587-96. doi: 10.1016/S0161-5890(01) 00099-2

27. Inoue H, Miyaji M, Kosugi A, Nagafuku M, Okazaki T, Mimori T, et al. Lipid rafts as the signaling scaffold for NK cell activation: tyrosine phosphorylation and association of LAT with phosphatidylinositol 3-kinase and phospholipase C- $\gamma$ following CD2 stimulation. Eur J Immunol (2002) 32:2188. doi: 10.1002/ 1521-4141(200208)32:8<2188::AID-IMMU2188>3.0.CO;2-T

28. Ferlazzo G, Morandi B. Cross-Talks between Natural Killer Cells and Distinct Subsets of Dendritic Cells. Front Immunol (2014) 5:159. doi: 10.3389/ fimmu.2014.00159

29. Haider AS, Lowes MA, Gardner H, Bandaru R, Darabi K, Chamian F, et al. Novel Insight into the Agonistic Mechanism of Alefacept In Vivo: Differentially Expressed Genes May Serve as Biomarkers of Response in Psoriasis Patients. J Immunol (2007) 178:7442-9. doi: 10.4049/jimmunol. 178.11.7442

30. Ashraf MI, Sarwar A, Kühl AA, Hunger E, Sattler A, Aigner F, et al. Natural Killer Cells Promote Kidney Graft Rejection Independently of Cyclosporine A Therapy. Front Immunol (2019) 10:2279. doi: 10.3389/fimmu.2019.02279

31. Ji W, Chen J, Mi Y, Wang G, Xu X, Wang W. Role of natural killer cells in liver transplantation treatment of liver cancer. Exp Ther Med (2017) 14:2380-4. doi: $10.3892 / \mathrm{etm} .2017 .4748$

32. Meehan AC, Mifsud NA, Nguyen THO, Levvey BJ, Snell GI, Kotsimbos TC, et al. Impact of Commonly Used Transplant Immunosuppressive Drugs on
Human NK Cell Function Is Dependent upon Stimulation Condition. PloS One (2013) 8:e60144. doi: 10.1371/journal.pone.0060144

33. Schleinitz N, Vély F, Harlé J-R, Vivier E. Natural killer cells in human autoimmune diseases. Immunology (2010) 131:451-8. doi: 10.1111/j.13652567.2010.03360.x

34. Fogel LA, Yokoyama WM, French AR. Natural killer cells in human autoimmune disorders. Arthritis Res Ther (2013) 15:216. doi: 10.1186/ar4232

35. Fehniger TA, Cooper MA, Nuovo GJ, Cella M, Faccetti F, Colonna M, et al. CD56bright natural killer cells are present in human lymph nodes and are activated by T cell-derived IL-2: a potential new link between adaptive and innate immunity. Blood (2003) 101:3052-7. doi: 10.1182/blood-2002-09-2876

36. Dehoux JP, Talpe S, Dewolf N, Otsuka M, Oike F, Jamar F, et al. Effects on human and nonhuman primate immune response of a new rat anti-CD2 monoclonal antibody. Transplantation (2000) 69:2622. doi: 10.1097/ 00007890-200006270-00024

37. Grandjean CL, Montalvao F, Celli S, Michonneau D, Breart B, Garcia Z, et al. Intravital imaging reveals improved Kupffer cell-mediated phagocytosis as a mode of action of glycoengineered anti-CD20 antibodies. Sci Rep (2016) 6. doi: $10.1038 /$ srep34382

Conflict of Interest: CB, FS, FC, SB, EB and DB are employees of ITB Med AB. SB, $\mathrm{EB}$, and DB own shares in ITB Med AB.

The authors declare that the research was conducted in the absence of any commercial or financial relationships that could be construed as a potential conflict of interest.

Copyright $(2021$ Binder, Sellberg, Cvetkovski, Berg, Berglund and Berglund. This is an open-access article distributed under the terms of the Creative Commons Attribution License (CC BY). The use, distribution or reproduction in other forums is permitted, provided the original author(s) and the copyright owner(s) are credited and that the original publication in this journal is cited, in accordance with accepted academic practice. No use, distribution or reproduction is permitted which does not comply with these terms. 